\title{
Periodontal Referral Patterns of General Dentists: Lessons for Dental Education
}

\author{
Jung Ho Lee; Duane E. Bennett; Philip S. Richards, D.D.S., M.S.; \\ Marita Rohr Inglehart, Dr. phil. habil.
}

Abstract: The objectives of this study were to investigate periodontal treatment and referral patterns and the considerations used in the process of dentists who make no periodontal referrals, relatively few referrals, or more referrals. Specifically, the role of disease characteristics, patient- and provider-related factors, attitudes towards periodontal referrals, and perceptions of dental education were explored. The relationships between the perceived quality of dental education concerning periodontal diagnosis and treatment and the considerations used in this process were evaluated as well. Data were collected from 160 members of the Michigan Dental Association using a mailed questionnaire. The respondents were predominantly male (77 percent) and white (96 percent) and had practiced for an average of twenty-three years $(\mathrm{SD}=10.7)$. While 13 percent of the respondents had not made any periodontal referrals during the past month, 69 percent had referred between one and five patients, and 18 percent more than five patients. Dentists who referred more than three patients per month considered the patients' oral hygiene as more important, had fewer patients from lower socioeconomic backgrounds and more patients with private insurance, and felt less well prepared by their dental education compared to general dentists who referred fewer than three patients per month to a periodontist. The more positively dentists evaluated their dental education in periodontics, the more conservative they were when considering percentage of bone loss as a basis for referral $(\mathrm{r}=.228 ; \mathrm{p}=.014)$, the more frequently they used systemic antibiotics in their treatment of periodontal disease $(\mathrm{r}=.180 ; \mathrm{p}=.036)$, and the more they considered whether their patients would return after the periodontal treatment $(\mathrm{r}=.185 ; \mathrm{p}=.028)$ as a factor in their referral decisions. General dentists' perceptions of the quality of their dental school education in periodontics decreased their willingness to refer patients and increased their desire to treat these patients in their own practices. Future research should analyze the ways in which dental school curricula could prepare students to make timely and necessary periodontal referrals.

\begin{abstract}
Mr. Lee is an Undergraduate Dental Student, University of Michigan, School of Dentistry; Mr. Bennett is an Undergraduate Dental Student, University of Michigan, School of Dentistry; Dr. Richards is Clinical Associate Professor, Department of Periodontics and Oral Medicine, University of Michigan, School of Dentistry; and Dr. Inglehart is Associate Professor of Dentistry, Department of Periodontics and Oral Medicine, School of Dentistry and Adjunct Associate Professor of Psychology, Department of Psychology, College of Literature, Science, and Arts, University of Michigan. Direct correspondence and requests for reprints to Dr. Marita Rohr Inglehart, Department of Periodontics and Oral Medicine, School of Dentistry, University of Michigan, 1011 North University Avenue, Ann Arbor, MI 48109-1078; 734-763-8073 phone; 734-763-5503 fax; mri@umich.edu.
\end{abstract}

Key words: referral, periodontal disease, comprehensive care, periodontal treatment, periodontal surgery, dental education, general dentists, periodontists

Submitted for publication 5/16/08; accepted 11/8/08

$\mathrm{P}$ eriodontal disease is one of the most common health care problems in the United States, with 80 percent or more adults experiencing periodontitis at some time during their lives and at least 20 percent having moderate to severe forms of periodontitis at any given time. ${ }^{1}$ Epidemiologic surveys showed that more than 50 percent of adults in the United States had gingivitis on three or four tooth sites, 67 percent had subgingival calculus, and 40 percent had attachment loss of at least $3.0 \mathrm{~mm}^{2}$ Given these statistics, general dentists need to be well prepared to treat periodontal diseases, and they also need to be well informed about how to make timely and appropriate referrals to periodontists when necessary. Recent studies provided evidence that this referral process might be compromised in many instances. For example, Dockter et al. ${ }^{3}$ found that 74 percent of patients who were referred to periodontists were diagnosed as type IV or with advanced periodontitis and that 29.8 percent of the referred patients needed two or more extractions because, at the time of referral, it was already too late for periodontal treatment. Furthermore, Cobb et al. ${ }^{4}$ found in a comparison of referral patterns between 1980 and 2000 that patients who were referred to periodontists from general dentists in 2000 exhibited a greater loss of teeth, had more severe periodontal disease, and required extraction of more teeth than did patients in 1980 .

These findings raise questions concerning how general dentists make periodontal referral decisions and how future dentists can be educated to use evi- 
dence-based dentistry ${ }^{5}$ and base referral decisions on sound diagnostic criteria. This study therefore investigated the factors used by general dentists when making treatment referrals for patients with periodontal disease. In addition, this study also explored the differences among a) nonreferring dentists versus $b$ ) dentists who refer a few patients versus c) dentists who refer more patients to periodontists concerning their considerations of disease characteristics, patient factors, provider-related factors, attitudes towards periodontal referrals, and perceptions of their dental education. Finally, the effects of the perceived quality of dental education concerning periodontal diagnosis and treatment in this process were evaluated as well.

Concerning the role of disease characteristics in the process of referring periodontal patients, Tugnait et al. ${ }^{6,7}$ in England and Wales found that there was little consistency between the referral patterns of general dentists and periodontists and the use of disease criteria in this process. For example, only 67 percent of the respondents concurred with the recommendation to use radiographs as a diagnostic tool when a periodontal/endodontic lesion was suspected. The authors concluded that there was considerable variation in the selection and use of radiographs among general dentists when diagnosing periodontal diseases. In the United States, the Academy Report of the American Academy of Periodontology from $2003^{8}$ described the many advances that have been made concerning the diagnosis of periodontal diseases with radiographic imaging methods. This report stated that radiographs are an essential component of a complete periodontal examination.

In addition to disease characteristics, patient factors such as smoking ${ }^{4}$ and the patient's willingness to cooperate with oral hygiene instructions also need to be considered when planning treatment for a patient with periodontal disease. Fardal et al., ${ }^{910}$ found, for example, that patients' cooperation with periodontists' treatment recommendations played an important role in the treatment process and especially in retaining teeth.

Some of the variations in general dentists' treatment of periodontal patients may be attributed to a lack of education while they attended dental school. In 2005, Darby et al. reported in their survey of 285 general dentists that most respondents felt confident to diagnose and treat gingivitis and initial periodontitis. ${ }^{11}$ However, only 61.9 percent of those dentists surveyed felt confident to diagnose aggressive/early onset periodontitis, about one-third (36.3 percent) were not confident about treating advanced periodontitis, and 51.6 percent were not confident about providing treatment for aggressive periodontitis. Based on these and other findings, it seems appropriate to assess the role of general dentists' level of training in the process of making referrals. ${ }^{12}$

General dentists' lack of confidence in managing periodontal disease and making appropriate referrals could possibly stem from changes in contemporary dental education. Cobb et al., for example, pointed out in 2003 that, a generation ago, dentists had more interaction with periodontists while in dental school than do more recent graduates. ${ }^{4}$ They argued that dental students in recent years received significantly less clinical education that was conducted by periodontists; rather, more instruction related to periodontal disease was provided by general dentists and dental hygienists. Cobb et al. reported that the average U.S. dental school curriculum in 2002 contained approximately 4,900 hours of instruction, but only 295 of these hours ( 6 percent) were devoted to periodontics.

In addition to these educational considerations, Cobb et al. also pointed out that younger graduates have to repay, on average, higher education loans at the time of their graduation from dental school than dentists in earlier cohorts. ${ }^{4}$ They speculated that this higher rate of debt could lead younger dentists to try to keep more patients in their own practices for periodontal treatment and for the maintenance portion of their periodontal treatment as opposed to having periodontists and their staffs provide this treatment. This practice pattern could potentially result in having less experienced and less well-trained dentists treat more periodontal patients because of financial reasons.

In 2007, Lanning et al. found that the most common periodontal surgical services performed by general dentists included crown lengthening and pocket reduction surgery, which were done by 38 percent and 21 percent of general dentists, respectively. ${ }^{13}$ They found that a few general dentists performed the majority of periodontal surgical services. Other researchers found that the factors that influence which specific types of treatment are provided by general dentists included the year of dental school graduation, the number of recent hours of continuing education related to periodontics, the combined number of dental hygienist days per week, the percentage of periodontal patients in a practice, and the percentage of referrals for nonsurgical periodontal therapy. ${ }^{11}$ In addition, female general dentists have been found to 
be more likely to refer more patients per month to a periodontist than do male general dentists. ${ }^{14}$ Dentists who practiced with one other dentist were found to be twice as likely to refer more frequently than solo practitioners or dentists in larger group practices. ${ }^{14}$ Finally, dentists employing more hygienists have been found to be more likely to refer patients than those with fewer hygienists. ${ }^{15}$

Referrals to periodontists may not be based on uniform standards. Some general dentists may not be aware of when to refer certain cases. ${ }^{11}$ Research by Linden et al. found that a considerable variation existed among general dentists in relation to the referral patterns for specialist periodontal advice and treatment. ${ }^{16,17}$ One way to encourage general dentists to be aware of the importance of periodontal treatment in a timely manner is to develop protocols for periodontal therapy that integrate important nonsurgical periodontal techniques, including scaling, root planing, and the use of local and systemic antibiotics and subantimicrobial chemotherapy. ${ }^{2}$ Although the British Society of Periodontology issued a very detailed and specific Referral Policy and Parameters of Care in 2002, ${ }^{18}$ efforts by the American Dental Association (ADA) and the American Academy of Periodontology (AAP) to develop a universal screening tool called Periodontal Screening and Recording (PSR) were strongly criticized. ${ }^{19}$ However, there seems to be a consensus in the literature that, for the majority of cases, the periodontal diagnosis should be made during the initial evaluation phase of patients' visits to general dentists and that general dentists should perform and record a complete probing examination for the proper diagnosis and management of periodontal disease. ${ }^{20,21}$ In an effort to improve the referral process from general dentists to periodontists, clinical guidelines on when to refer periodontal patients were published by the Academy of General Dentistry. ${ }^{2}$ These guidelines suggest that the decision must be made in each individual practice, considering a host of factors, and that it is inadvisable to treat a disease without an adequate understanding of the disease process and its effect on the individual.

In addition, Suzuki recommended that general dentists should refer when pocket depths are larger than $3 \mathrm{~mm}$ and then to consider a number of subsequent steps. ${ }^{22}$ This Suzuki model and similar considerations proposed by Trovato ${ }^{2}$ concerning which factors should be included when making a diagnosis and planning treatment were used as a basis to design a questionnaire that was first used by Patel et al. ${ }^{23}$ Patel et al. used this survey to assess which factors periodontists consider when making treatment recommendations. This same survey was again used in this study to explore whether general dentists consider the set of variables when making referrals to periodontists that Suzuki ${ }^{22}$ and Trovato $^{2}$ described as necessary factors that should be included in the diagnosis and treatment planning for patients with periodontal disease.

In addition to making referrals based on the clinical condition of the patient, it has been found that many referrals are based on the relationship between the general practitioner and the periodontist and especially on the communication between these professionals. ${ }^{15,24}$ Unfortunately, a lack of communication between general practitioners and periodontists has been found to be a significant barrier to effective patient referrals. ${ }^{25}$ Often, general dentists may not note in the patient record or otherwise convey important health concerns such as heart conditions, mental illness, and blood diseases/hemophilia to periodontists when making a referral. However, attention to systemic conditions is crucial when treating periodontal disease. ${ }^{26}$

Finally, the characteristics of the patients in a general dental practice also affect how referrals are made. For instance, general dentists may refer older and less educated patients more frequently than they do younger and more educated patients. ${ }^{27}$

The aims of our study were to a) explore which factors affect the periodontal referral patterns of general dentists, b) investigate whether dentists who never refer or refer very few patients to periodontists differ in their referral considerations from dentists who refer more patients, and c) assess how general dentists' perceptions of their educational preparation in dental school for diagnosis and treatment of patients with periodontal disease affect their referral decisions.

\section{Methods and Materials}

This research was approved by the Institutional Review Board for the Health Sciences at the University of Michigan, Ann Arbor, MI (\#HUM00010159).

During the summer of 2007, a survey was mailed to a random sample of 500 members of the Michigan Dental Association (MDA). Three surveys could not be delivered due to faulty addresses. A total of 160 members responded, which resulted in a response rate of 32 percent. The respondents ranged in age from twenty-six to eighty-six years (mean: 50 
years; SD: 10.9). They were predominantly male (77 percent) and white (96 percent) and practiced in solo practices (66 percent). An analysis of the location of the dental offices showed that 13 percent were situated in rural areas, 23 percent in small towns, 34 percent in moderate-sized cities, 21 percent in suburbs, and 10 percent in large cities.

The survey was mailed with a cover letter written by the dean of the University of Michigan School of Dentistry. This letter explained the purpose of the study and asked for the anonymous return of the survey in a provided stamped, self-addressed return envelope.

The survey was adapted from earlier research by Patel et al. in a study exploring periodontists' considerations of patient factors for the periodontal treatment process. ${ }^{23}$ The initial survey had been developed based on the considerations presented by Suzuki ${ }^{22}$ and Trovato ${ }^{2}$ concerning the factors that should be considered when making periodontal diagnosis and planning periodontal treatment. Patel et al. used this survey to collect data from members of the American Academy of Periodontology to collect information about the treatment planning process. To be able to use this survey for our study, the questions in the prior survey - which focused on treatment planning in general-were changed to center on only one part of the treatment planning process, namely, making referrals to periodontists. The revised survey had four parts. The first section contained questions concerning respondents' sociodemographic and educational background as well as their practice characteristics. The second section consisted of questions concerning how the respondents care for patients with periodontal disease, such as the number of patients requiring periodontal treatment and the type of care provided for these patients. The third section consisted of questions about the factors the respondents consider when referring patients for periodontal treatment. Finally, the respondents were asked whether their dental education prepared them well to provide periodontal treatment, whether they had received any postgraduate education about periodontal treatment, and whether they intended to attend any continuing education courses about periodontal therapy.

The data were analyzed with SPSS (Version 14.0). ${ }^{28}$ Descriptive statistics such as frequency distributions, measures of central tendency, and variability were used to provide a general overview of the findings. Analyses of variance were used to compare the average responses of providers who referred zero vs. one to five vs. more than five patients per week to a periodontist. Pearson correlation coefficients were computed to assess the relationships between the ratings of the quality of dental education and the degrees to which various factors were seen as relevant for diagnosing and treating periodontal patients.

\section{Results}

An analysis of the practice characteristics concerning the treatment and referral of patients with periodontal disease showed that 33 percent of the general dentists reported that they diagnosed between zero and five patients with periodontal disease in an average week; 34 percent reported that they encountered between six and ten periodontal patients per week; and 33 percent indicated that they saw more than ten patients with periodontal disease in this time span.

Responses to questions about who provides care for periodontal patients showed that over half of the general dentists ( 59 percent) reported that they themselves do not personally treat any periodontal patients in an average week, while 35 percent treated between one and five of these patients a week, and 7 percent treated more than five patients in an average week. Concerning treatment of periodontal patients by dental hygienists, 14 percent reported that their hygienists did not treat patients with periodontal disease, 32 percent that their hygienists treated between one and five periodontal patients in an average week, and 54 percent that their hygienists treated more than five patients in a week. The majority of the dentists (69 percent) reported that they refer one to five periodontal patients in an average week, while 23 percent never refer any patient, and 7 percent refer more than five periodontal patients in an average week (see Table 1). In addition, the respondents indicated the number of periodontal patients they referred during the last month. While approximately the same percentage of providers ( 69 percent) reported referring between one and five patients during the last month, 13 percent referred no patients, and 18 percent referred more than five patients.

The respondents were also asked how often they themselves and their hygienists provide various kinds of periodontal therapy, such as nonsurgical treatment, local antibiotics, or periodontal surgery. Survey respondents reported that 80 percent of their hygienists often provide nonsurgical treatment, 15 percent sometimes, and only 5 percent never provide nonsurgical treatment. Twenty-seven percent of the 
Table 1. Percentages/means of responses concerning the treatment of patients with periodontal disease

\begin{tabular}{|c|c|c|c|c|}
\hline & $\begin{array}{l}0-5 \text { patients } \\
\text { per av. week }\end{array}$ & $\begin{array}{l}6-10 \text { patients } \\
\text { per av. week }\end{array}$ & $\begin{array}{l}>10 \text { patients } \\
\text { per av. week }\end{array}$ & $\begin{array}{l}\text { Mean } \\
(\mathrm{SD})\end{array}$ \\
\hline \multirow[t]{2}{*}{$\begin{array}{l}\text { Number of patients requiring periodontal } \\
\text { treatment }\end{array}$} & $32.6 \%$ & $34.1 \%$ & $33.3 \%$ & $\begin{array}{c}12.32 \\
(11.902)\end{array}$ \\
\hline & $\begin{array}{c}0 \text { patients } \\
\text { per av. week }\end{array}$ & $\begin{array}{l}1-5 \text { patients } \\
\text { per av. week }\end{array}$ & $\begin{array}{l}>5 \text { patients } \\
\text { per av. week }\end{array}$ & \\
\hline Number of patients treated by a dentist & $58.7 \%$ & $34.8 \%$ & $6.5 \%$ & $\begin{array}{c}1.40 \\
(2.984)\end{array}$ \\
\hline Number of patients treated by a hygienist & $13.8 \%$ & $31.9 \%$ & $54.3 \%$ & $\begin{array}{c}10.12 \\
(12.803)\end{array}$ \\
\hline \multicolumn{2}{|c|}{ Number of patients referred to a periodontist $23.4 \%$} & $69.3 \%$ & $7.3 \%$ & $\begin{array}{c}2.46 \\
(5.653)\end{array}$ \\
\hline & $\begin{array}{l}0 \text { patients } \\
\text { last month }\end{array}$ & $\begin{array}{l}1-5 \text { patients } \\
\text { last month }\end{array}$ & $\begin{array}{l}>5 \text { patients } \\
\text { last month }\end{array}$ & \\
\hline \multicolumn{2}{|c|}{ Number of patients referred to a periodontist $13.4 \%$} & $69.0 \%$ & $17.6 \%$ & $\begin{array}{c}4.01 \\
(5.008)\end{array}$ \\
\hline & $1=$ Never & $2=$ Sometimes & $3=$ Often & \\
\hline \multicolumn{5}{|l|}{ Dentist provides: } \\
\hline nonsurgical treatment & $42.5 \%$ & $30.1 \%$ & $27.4 \%$ & $1.85(0.825)$ \\
\hline local antibiotics & $50.0 \%$ & $40.3 \%$ & $9.7 \%$ & $1.60(0.662)$ \\
\hline systemic antibiotics & $48.6 \%$ & $45.2 \%$ & $6.2 \%$ & $1.58(0.608)$ \\
\hline Periostat & $67.1 \%$ & $29.4 \%$ & $3.5 \%$ & $1.36(0.551)$ \\
\hline periodontal surgery & $75.7 \%$ & $22.9 \%$ & $1.4 \%$ & $1.26(0.469)$ \\
\hline \multicolumn{5}{|l|}{ Hygienist provides: } \\
\hline nonsurgical treatment & $4.9 \%$ & $14.7 \%$ & $80.4 \%$ & $2.76(0.534)$ \\
\hline local antibiotics & $50.7 \%$ & $31.2 \%$ & $18.1 \%$ & $1.67(0.766)$ \\
\hline systemic antibiotics & $76.8 \%$ & $18.1 \%$ & $5.1 \%$ & $1.28(0.554)$ \\
\hline Periostat & $63.3 \%$ & $28.8 \%$ & $7.9 \%$ & $1.45(0.639)$ \\
\hline
\end{tabular}

dentists reported that they often treat periodontal patients nonsurgically, 30 percent sometimes, and 43 percent indicated that they never provide this type of care. Very few dentists said they treat their patients with periodontal disease "often" with local (10 percent) or systemic antibiotics (6 percent); 50 percent said they never use local antibiotics; and 49 percent said they never use systemic antibiotics. The remaining respondents indicated that they "sometimes" use local (40 percent) or systemic (45 percent) antibiotics. Very few dentists indicated that they performed periodontal surgery often ( 1 percent) or sometimes (23 percent) or that they used adjunctive enzyme suppression chemotherapy (Periostat) often (4 percent) or sometimes (29 percent).

Tables 2 and 3 show the degree to which dentists who made no periodontal referrals during the month prior to the survey differed from providers with one to three referrals and from dentists with more than three referrals during the same time span.

The first group of factors analyzed was disease characteristics, such as the probing pocket depth in millimeters $(\mathrm{mm})$ required to consider extraction, recommend extraction, and refer a patient for periodontal treatment. As shown in Table 2, while providers who did not refer periodontal patients already recommended extraction at $9.31 \mathrm{~mm}$ pocket depth, providers with one to three referrals recommended extractions for patients with a slightly higher average probing pocket depth of $9.61 \mathrm{~mm}$, and respondents with more than three referrals during the last month indicated that they would recommend extractions for patients with a higher average probing pocket depth of $10.68 \mathrm{~mm}(\mathrm{p}=.019)$. The consideration of disease 
Table 2. Average responses concerning disease and patient characteristics used by nonreferring vs. referring dentists when making treatment recommendations

$\begin{array}{lcc}\begin{array}{l}\text { No referrals } \\ \text { last month }\end{array} & 1-3 \text { referrals } & >3 \text { referrals } \\ \text { last month } & \text { last month }\end{array}$

\section{Disease Characteristics}

$\mathrm{mm}$ pocket depth: consider extraction

$\begin{array}{rrrr}8.54 & 8.51 & 9.22 & .096 \\ 9.31 & 9.61 & 10.68 & .019 \\ 5.50 & 6.34 & 6.13 & .175 \\ 38.00 & 38.87 & 36.03 & .709\end{array}$

$\mathrm{mm}$ pocket depth: recommend extraction

38.87

175

$\%$ bone loss: for referral

\section{Patient Factors ${ }^{\mathrm{a}}$}

How much do the following factors affect your decision to refer a patient?

$\begin{array}{lllll}\text { Age } & 2.06 & 2.65 & 2.89 & .142 \\ \text { General health } & 2.56 & 3.09 & 3.31 & .122 \\ \text { Dental fear } & 1.81 & 2.18 & 1.89 & .239 \\ \text { Oral hygiene } & 2.75 & 2.96 & 3.57 & .024 \\ \text { "Dental IQ" } & 2.81 & 2.81 & 3.02 & .669 \\ \text { Desire to see a specialist } & 3.75 & 3.87 & 3.70 & .785 \\ \text { Ability to pay } & 1.75 & 2.45 & 2.19 & .118\end{array}$

${ }^{a}$ The answers to these questions were given on an answer scale ranging from $1=$ not at all to $5=$ very much.

Table 3. Average responses concerning provider-related factors used by nonreferring vs. referring dentists when making treatment recommendations

\begin{tabular}{cccc} 
Mean & Mean & Mean \\
\hline $\begin{array}{c}\text { 0 referrals } \\
\text { last month }\end{array}$ & $\begin{array}{c}1-3 \text { referrals } \\
\text { last month }\end{array} \quad \begin{array}{c}>3 \text { referrals } \\
\text { last month }\end{array} \quad p$
\end{tabular}

\section{Treatment Patterns ${ }^{\mathrm{a}}$}

last month

last month

last month

Nonsurgical treatment ${ }^{b}$

Use of local antibiotics ${ }^{b}$

Use of systemic antibiotics ${ }^{b}$

Treatment with Periostat ${ }^{b}$

Periodontal surgery by general dentist

Practice Characteristics

$\%$ patients with high socioeconomic status

12.30

$\%$ patients with low socioeconomic status

$\%$ patients covered by private insurance

\section{Referral Considerations}

Location of periodontal practice ${ }^{c}$

Relationship with periodontist ${ }^{c}$

I would like to treat more perio disease in my office ${ }^{\mathrm{d}}$

I prefer not to refer for periodontal therapy ${ }^{\mathrm{d}}$

Educational Characteristics $^{\mathbf{d}}$

Dental education prepared me well for perio therapy

I would like to attend CE courses about perio therapy
2.24

1.68

1.47

1.47

1.32

37.28

2.30

1.70

1.44

1.47

1.33

24.28

16.84

71.03

3.39

4.09

2.85

1.95

2.25

4.00

3.13
3.40

3.16

\subsection{0}

1.43

1.36

1.24

1.11

19.18

27.09

67.54

3.40

4.30

3.26

1.45

3.09

3.54

010

.100

aThe answers to these questions were given on an answer scale from $1=$ never to $2=$ sometimes to $3=$ often.

${ }^{b}$ The answers concerning the frequencies with which a) dentists personally and b) dental hygienists in their practices provide these types of treatments were averaged.

${ }^{\mathrm{c}}$ The answers to these questions were given on a five-point answer scale ranging from $1=$ not at all to $5=$ very much.

${ }^{\mathrm{d}}$ The answers to these questions were given on a five-point answer scale ranging from $1=$ strongly disagree to $5=$ strongly agree. 
characteristics for referral decisions did not differ among these three groups of providers.

While these three groups of respondents did not differ significantly in the degree to which they considered the patient's age, general health, and ability to pay when making a referral, Table 2 shows that they did differ in the degree to which they considered the patient's oral hygiene efforts in this context. Dentists with more than three referrals during the last month indicated that they considered the patient's oral hygiene efforts more strongly with a mean of 3.57 on a five-point scale ranging from $1=$ not at all to $5=$ very much than dentists who referred between one and three patients (2.96) or never referred a patient during the past month (2.75). The difference among these three means was statistically significant $(\mathrm{p}=.024)$.

Table 3 indicates the degree to which these three groups of dentists differed in their consideration of treatment patterns, practice characteristics, referral considerations, and their educational background concerning periodontal therapy. Providers who referred more than three patients during the last month were less likely to use Periostat and periodontal surgery than were providers who less often or never referred patients during the past month. The three groups of dentists differed significantly in the percentages of patients in their practices with a high or a low socioeconomic status or with coverage by private insurance. Dentists who made no referrals to a periodontist during the past month had the lowest percentage of patients with a high socioeconomic status (12.30 percent), the highest percentage of patients with a low socioeconomic status (37.28 percent), and the lowest percentage of patients with private insurance (56.56 percent) compared to dentists who referred between one and three patients (high socioeconomic status: 24.28 percent; low socioeconomic status: 16.84 percent; private insurance: 71.03 percent) or over three patients (19.18 percent, 27.09 percent, 67.54 percent, respectively) during the past month.

The three groups of providers also differed in the degree to which they considered various referral characteristics. Dentists who referred more than three patients had the lowest level of agreement with the statement "I prefer not to refer for periodontal therapy." This response indicated that the providers' attitudes and behavior were consistent. However, the trend that the more frequently referring dentists agreed more strongly that they would like to treat more periodontal disease in their own offices compared to the nonreferring and less often referring den- tists showed that an increased number of referrals did not necessarily indicate a lack of interest in providing periodontal care. One final referral consideration in which the dentists in the three groups differed was the location of the periodontal practice. Nonreferring dentists on average downplayed the importance of this factor (five-point scale: 1=disagree strongly to $5=$ agree strongly: 2.38), while dentists with one to three referrals or with more than three monthly referrals responded more neutrally to it (3.39 to $3.40 ; \mathrm{p}=.018$ ).

Finally, the dentists with more referrals during the past month reported that their dental education had prepared them less well (3.09) than the dentists who referred less often (3.40) or never referred (4.00; $\mathrm{p}=0.10)$ on a rating scale that ranged from $1=$ strongly disagree to $5=$ strongly agree. General dentists who never or less often referred patients were not as interested in participating in continuing education courses about periodontal therapy as the more frequently referring dentists.

In order to gain a better understanding of the effects of the respondents' dental education on periodontal referral patterns, correlations were computed between responses to the questions concerning how well their dental education had prepared them to treat patients with periodontal disease and the various factors that might be considered when making periodontal referrals. Tables 4 and 5 show the results concerning the relationships between the level of agreement with the questions "My dental education prepared me well to provide periodontal treatment" and "I would like to attend CE courses about periodontal therapy" and the factors the providers considered when making referrals. The better the respondents evaluated their dental education about periodontal therapy, the more conservative they were in the use of disease characteristics when considering extraction $(\mathrm{r}=.193 ; \mathrm{p}=.037)$ and when making referrals (Table 4). For example, the more they agreed that they were well educated, the higher the percentage of bone loss was required to make a referral to a periodontist $(\mathrm{r}=.228 ; \mathrm{p}=.014)$.

While not a single patient background factor was correlated significantly with the perceived quality of their dental education, the respondents' assessment of their dental education correlated significantly with the types of treatment used when providing periodontal care (Table 5). The better the dentists were educated, the more often they used systemic antibiotics $(\mathrm{r}=.180 ; \mathrm{p}=.036)$ and the more they provided treatment with Periostat $(\mathrm{r}=.179 ; \mathrm{p}=.037)$ or 
Table 4. Correlations between the responses concerning dental education and the disease characteristics and patient factors affecting treatment decisions

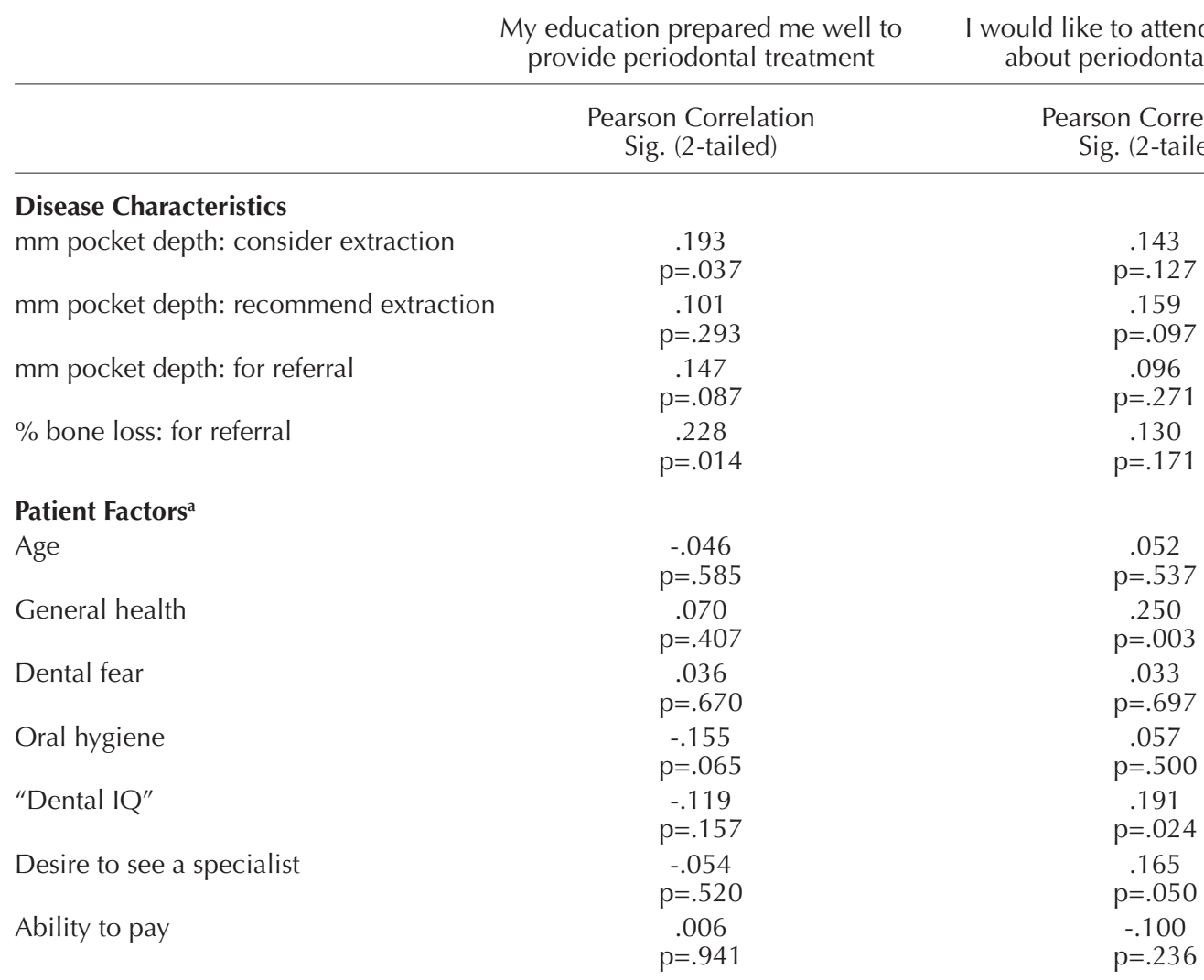

The answers to these questions were given on an answer scale ranging from $1=$ not at all to $5=$ very much.

performed periodontal surgery $(r=.177 ; \mathrm{p}=.034)$. In addition, the better the dentists rated their periodontal education, the more they wanted their patients to return to their own practice after treatment by the periodontist $(\mathrm{r}=.185 ; \mathrm{p}=.028)$.

Concerning the degree to which the dentists were interested in continuing education (CE) courses about periodontal treatment, the data showed that the more the respondents wanted to treat more periodontal patients in their own practice, the more they wanted to participate in CE courses about periodontal therapy $(\mathrm{r}=.451 ; \mathrm{p}<.001)$.

\section{Discussion}

Approximately one-third of the respondents (32.6 percent) reported seeing between zero and five patients with periodontal disease in an average week. This finding is surprising given that, at any time,
20 percent of the U.S. population is experiencing moderate to severe periodontitis and that 80 percent of the U.S. population will experience periodontal disease at least once in their lifetime. ${ }^{1}$ Considering this situation, one could potentially argue that general dentists might underdiagnose periodontal disease. If this interpretation is accurate, the findings could indicate that a lack of periodontal referrals could potentially be related to a lack of diagnostic skills and therefore more emphasis should be placed on educating dentists about diagnosing periodontal disease in its early stages.

While there is no way of knowing if the oral health of the patients seen in the practices of the responding general dentists in this study reflects national patterns, it is noteworthy that more than half of the responding dentists (58.7 percent) reported that they did not provide periodontal treatment in an average week and, more specifically, that they did not ever provide nonsurgical periodontal treatment 
Table 5. Correlations among the responses concerning dental education and treatment patterns, practice characteristics, and referral considerations affecting treatment decisions

\begin{tabular}{|c|c|c|}
\hline \multicolumn{2}{|c|}{$\begin{array}{l}\text { My education prepared me well to } \\
\text { provide periodontal treatment }\end{array}$} & $\begin{array}{l}\text { I would like to attend CE courses } \\
\text { about periodontal therapy }\end{array}$ \\
\hline & $\begin{array}{l}\text { Pearson Correlation } \\
\text { Sig. (2-tailed) }\end{array}$ & $\begin{array}{l}\text { Pearson Correlation } \\
\text { Sig. (2-tailed) }\end{array}$ \\
\hline \multicolumn{3}{|l|}{ Treatment Patterns $^{\mathrm{a}}$} \\
\hline Nonsurgical treatment & $\begin{array}{c}.147 \\
p=.082\end{array}$ & $\begin{array}{c}.234 \\
p=.006\end{array}$ \\
\hline Local antibiotics & $\begin{array}{c}.154 \\
\mathrm{p}=.073\end{array}$ & $\begin{array}{l}.130 \\
p=.135\end{array}$ \\
\hline Systemic antibiotics & $\begin{array}{c}.180 \\
p=.036\end{array}$ & $\begin{array}{c}.156 \\
p=.073\end{array}$ \\
\hline Treatment with Periostat & $\begin{array}{l}.179 \\
\mathrm{p}=.037\end{array}$ & $\begin{array}{c}.003 \\
p=.969\end{array}$ \\
\hline Periodontal surgery by a general dentist & $\begin{array}{c}.177 \\
\mathrm{p}=.034\end{array}$ & $\begin{array}{c}-.013 \\
\mathrm{p}=.878\end{array}$ \\
\hline \multicolumn{3}{|l|}{ Practice Characteristics } \\
\hline$\%$ patients with high socioeconomic status & $\begin{array}{l}.139 \\
p=.103\end{array}$ & $\begin{array}{c}-.119 \\
p=.169\end{array}$ \\
\hline$\%$ patients with low socioeconomic status & $\begin{array}{c}.009 \\
p=.919\end{array}$ & $\begin{array}{c}-.001 \\
\mathrm{p}=.989\end{array}$ \\
\hline$\%$ patients covered by private insurance & $\begin{array}{c}.020 \\
\mathrm{p}=.818\end{array}$ & $\begin{array}{c}.067 \\
p=.434\end{array}$ \\
\hline \multicolumn{3}{|l|}{ Referral Considerations } \\
\hline Location of periodontal practice ${ }^{b}$ & $\begin{array}{c}-.163 \\
p=.052\end{array}$ & $\begin{array}{c}.082 \\
p=.338\end{array}$ \\
\hline Relationship with the periodontist ${ }^{\mathrm{b}}$ & $\begin{array}{c}.164 \\
\mathrm{p}=.051\end{array}$ & $\begin{array}{l}-.043 \\
p=.616\end{array}$ \\
\hline Return of patient after treatment ${ }^{b}$ & $\begin{array}{c}.185 \\
\mathrm{p}=.028\end{array}$ & $\begin{array}{c}.144 \\
\mathrm{p}=.091\end{array}$ \\
\hline $\begin{array}{l}\text { I would like to treat more periodontal } \\
\text { disease in my office }\end{array}$ & $\begin{array}{l}-.102 \\
p=.226\end{array}$ & $\begin{array}{c}.451 \\
\mathrm{p}<.001\end{array}$ \\
\hline $\begin{array}{l}\text { I prefer not to refer for periodontal } \\
\text { therapyc }\end{array}$ & $\begin{array}{l}-.055 \\
\mathrm{p}=.515\end{array}$ & $\begin{array}{l}-.099 \\
\mathrm{p}=.246\end{array}$ \\
\hline
\end{tabular}

(42.5 percent), local antibiotics ( 50 percent), systemic antibiotics (48.6 percent), or periodontal surgery (75.7 percent). A comparison of the high percentages of patients with periodontal disease in the U.S. population with the frequency of periodontal care reported by the general dentists in this study could raise concerns about the degree to which adequate treatment is provided for periodontal patients. This situation should alert dental educators to examine the adequacy of periodontics education in the dental school curricula as has been advocated by Cobb et al. and Fardal et al., ${ }^{4}$ These findings suggest that enhanced opportunities for CE programs concern- ing the treatment of periodontal patients might be indicated.

An analysis of responses to the two questions concerning the number of periodontal referrals showed that the respondents indicated that they referred an average of 2.33 patients to a periodontist in an average week. However, they also reported that during the past month they had referred an average of 4.07 patients to a periodontist. The comparison of these two responses is interesting because it indicates that the respondents might overestimate the number of periodontal referrals in general, but might be more accurate when they think concretely about the number 
of their most recent referrals during the past month. It seemed therefore more valid to use the concrete number of referrals during the past month as the reference number in these analyses.

Considering the number of periodontal referrals made, it is important to realize that a substantial percentage of dentists (23.4 percent) responded that they refer no patients in an average week and that 13.4 percent said they did not refer any periodontal patients during the past month. One potential explanation for this finding could be that general dentists do not refer periodontal patients when they practice in an area where it is too far or too difficult for a patient to access care from a periodontist. One might therefore expect that a lack of referrals is due to the location of the general dentists' practice in a rural area and that dentists located in larger cities or suburbs of cities might refer more patients because their practices are closer to periodontists' offices. This explanation, however, was not supported by the data. There was no significant correlation between the location of the general dentists' offices (assessed with the five categories: rural $<5,000$; small town or city 5,000-24,999; moderate-sized city 25,000-250,000; suburb near large city; large city) and the number of referrals made. On the contrary, the degree to which dentists considered the location of the periodontists' offices increased with the number of referrals made, meaning that referring dentists considered the location of the periodontists' offices significantly more than nonreferring dentists.

These results need to be considered in connection with the findings of Dockter et al., ${ }^{3}$ who found that periodontal referrals were often made too late to allow appropriate periodontal treatment by specialists. If some patients do not have the opportunity to be referred because their general dentists do not refer periodontal patients, then the degree to which patients do not receive adequate professional care is even higher than suggested by Dockter et al.

The considerations concerning how to educate future dentists about referrals go beyond merely considering periodontal referral processes. Christopherson et al. ${ }^{29,30}$ found, for example, that general dentists might refer more patients for orthodontic treatment than is justified by an objective assessment of these patients with an index of orthodontic treatment need. This behavior pattern of potential overtreatment of orthodontic patients should be considered as an additional indicator that education about proper referral processes needs to be revisited.
In addition, it is worthwhile to consider which factors beyond disease characteristics might be considered by general dentists when making referral decisions. Practice characteristics are an important group of factors that might be highly relevant to referral patterns. For example, dentists who reported that they had many periodontal patients did not necessarily refer more patients than dentists who reported that they had fewer patients with periodontal disease. In fact, the respondents reported that the vast majority of periodontal treatment was completed at their own offices. However, the type of treatment provided and whether this treatment was provided by the dentist or a dental hygienist again differed among the practices.

One final consideration is concerned with the way the additional factors were assessed. In our study, the general dentists self-reported the degrees to which other factors such as practice characteristics, patient factors, or their own referral considerations affected their periodontal treatment decisions. These self-reports might be honest perceptions, but might not always objectively reflect reality. For example, the three groups of respondents with different numbers of referrals did not differ significantly in the degree to which they reported that they considered the patients' ability to pay for periodontal treatment. Nevertheless, the percentages of patients with low socioeconomic status, with high socioeconomic status, and with private insurance coverage varied significantly. The fewer low socioeconomic status patients the providers had, the fewer referrals they made. This fact contradicts the responses concerning the lack of differences between the groups of dentists concerning their subjective assessment of the importance of patients' ability to pay. While this study explored the differences between referring and nonreferring dentists, future research might continue this investigation by using more objective indicators in the analyses. Data from patient charts could, for example, provide more objective information than was assessed in this first exploratory study.

Finally, the results concerning the role of dental education in the periodontal referral process (see Tables 4 and 5) should alert all dental educators to evaluate how best to educate future providers so they understand which types of periodontal therapy are appropriate for the general dentist's scope of practice and when referrals to a periodontist are necessary. 


\section{Limitations}

One potential limitation of this study is the low response rate). However, given that this study was a first exploration of this area of interest, these findings can be used, despite this lower response rate, as a basis to investigate these issues further.

A second potential limitation is the fact that only general dentists from the state of Michigan were recruited to participate in this study. One might argue that the majority of dentists in this state graduated from one of the two dental schools in Michigan and that dentists who graduated from schools in other states might differ in their evaluation of their dental education concerning periodontal therapy and referrals. This consideration should alert dental educators in other U.S. states and internationally to assess the learning experiences provided for their students in periodontal therapy and the associated referral processes.

Finally, it is desirable for future research to go beyond general dentists' self-reports of practice behaviors and assess factors affecting referral processes more objectively.

\section{Conclusions}

These results support the studies of other researchers ${ }^{3,4}$ who found that periodontal referral processes need to be reanalyzed to ensure that patients receive the best periodontal care available. Substantial percentages of general dentists do not refer any patients for periodontal treatment or refer very few patients on average. This situation can put patients at risk for receiving substandard care.

Dental educators have to seriously consider how future dentists should be educated about a) making appropriate periodontal treatment decisions, b) actually providing optimal treatment, and c) referring periodontal patients in a timely fashion.

\section{Acknowledgments}

This research was supported by a Student Research Program Fellowship from the University of Michigan School of Dentistry to the first author. Additional support for the materials needed was provided by the Department of Periodontics and Oral Medicine (Chair: Dr. Laurie McCauley) at the University of Michigan School of Dentistry.
We want to thank Dean Peter Polverini for writing a cover letter for the mailing of the survey and the Michigan Dental Association for providing us with the address labels.

\section{REFERENCES}

1. Oral health in America: a report of the surgeon general. Rockville, MD: U.S. Department of Health and Human Services, National Institute of Dental and Craniofacial Research, National Institutes of Health, 2000.

2. Trovato JP. The role of the general dentist in periodontal care. Gen Dent 2003;51(2):176-81.

3. Dockter KM, Williams KB, Bray KS, Cobb CM. Relationship between prereferral periodontal care and periodontal status at time of referral. J Periodontol 2006;77:1708-16.

4. Cobb CM, Carrara A, El-Annan E, Youngblood LA, Becker BE, Becker W, et al. Periodontal referral patterns, 1980 versus 2000: a preliminary study. J Periodontol 2003;74(10):1470-4.

5. Hackshaw AK, Paul EA, Davenport ES. Evidence-based dentistry: an introduction. Copenhagen: Blackwell Munksgaard, 2006.

6. Tugnait A, Clerehugh V, Hirschmann PN. Use of the basic periodontal examination and radiographs in the assessment of periodontal diseases in general dental practice. $\mathrm{J}$ Dent 2004;32(1):17-25.

7. Tugnait A, Carmichael F. Use of radiographs in the diagnosis of periodontal disease. Dent Update 2005;32(9): 536-8.

8. American Academy of Periodontology. Academy report: diagnosis of periodontal diseases. J Periodontol 2003;74(8):1237-47.

9. Fardal O, Johannessen AC, Linden GJ. Tooth loss during maintenance following periodontal treatment in a periodontal practice in Norway. J Clin Periodontol 2004;31(7):550-5.

10. Fardal O. Interviews and assessments of returning noncompliant periodontal maintenance patients. J Clin Periodontol 2006;33(3):216-20.

11. Darby IB, Angkasa F, Duong C, Ho D, Legudi S, Pham K, Welsh A. Factors influencing the diagnosis and treatment of periodontal disease by dental practitioners in Victoria Aust Dent J 2005;50(1):37-41.

12. McQuistan MR, Kuthy RA, Damiano PC, Ward MM. General dentists' referral of 3- to 5-year-old children to pediatric dentists. J Am Dent Assoc 2006;137(5):653-60.

13. Lanning SK, Best AM, Hunt RJ. Periodontal services rendered by general practitioners. J Periodontol 2007;78(5):823-32.

14. Zemanovich MR, Bogacki RE, Abbott DM, Maynard JG Jr, Lanning SK. Demographic variables affecting patient referrals from general practice dentists to periodontists. J Periodontol 2006;77(3):341-9.

15. Townsend C. Team care for periodontal disease: a model for patient rights. Dent Today 2004;23(12):72,74-5.

16. Linden GJ, Stevenson M, Burke FJ. Variation in periodontal referral in 2 regions in the UK. J Clin Periodontol 1999;26(9):590-5. 
17. Linden GJ. Variation in periodontal referral by general practitioners. J Clin Periodontol 1998;25(8):655-61.

18. Dowell P, Chapple IL, British Society of Periodontology. The British Society of Periodontology referral policy and parameters of care. Dent Update 2002;29(7):352-3.

19. Charles CJ, Charles AH. Periodontal screening and recording. J Calif Dent Assoc 1994;22:43-6.

20. Snoad R. Description of a system designed to assist primary dental care clinicians in decision-making with regard to specialist periodontal referrals and report of two clinical audits using the system. Prim Dent Care 2005;12(4):135-41.

21. Starr CB, Collins JF. Determining when to refer periodontal patients: clinical guidelines. Gen Dent 1999;47(4): $381-4$.

22. Suzuki JB. Blurred relationship between periodontist and the general practitioner. Alpha Omegan 2000;93(4): 19-25.

23. Patel A, Richards PS, Inglehart MR. Periodontists' considerations of patient factors for the treatment process. $\mathrm{J}$ Dent Res 2006;85(A):Abstract 1166.
24. Sharpe G, Durham JA, Preshaw PM. Attitudes regarding specialist referrals in periodontics. Br Dent J 2007;202(4): E11, discussion 218-9.

25. Kourkouta S, Darbar UR. An audit of the quality and content of periodontal referrals and the effect of implementing referral criteria. Prim Dental Care 2006;13(3):99-106.

26. Breedlove G. Prioritizing oral health in pregnancy. Kansas Nurse 2004;79(10):4-6.

27. Michigan Dental Association. Guidelines for management of patients with periodontal disease. J Mich Dent Assoc 2006;88(10):24.

28. SPSS Inc. SPSS 14.0 Student Version for Windows (SA). Prentice Hall, 2006.

29. Christopherson EA, Briskie D, Inglehart MR. Objective, subjective, and self-assessment of preadolescent orthodontic treatment need: a function of age, gender, and ethnic/ racial background? J Public Health Dent, forthcoming.

30. Christopherson EA, Briskie D, Inglehart MR. Preadolescent orthodontic treatment need: objective and subjective provider assessments and patient self-reports. Am J Orthod Dentofacial Orthop, forthcoming. 